\title{
Classical conditioning of the nictitating membrane response in the domestic chick
}

\author{
JOEL L. DAVIS \\ Veterans Administration Hospital, Sepulveda, California 91343 \\ and \\ STEVEN R. COATES \\ University of California, Irvine, California 92717
}

\begin{abstract}
The neuropharmacology and neuroanatomy of the domestic chicken (both developing and mature) has been described in detail. In addition, a wide variety of behavioral tasks has been used to study learning in chicks. In order to increase their usefulness as subjects in psychobiological experiments, we examined them in a paradigm where learning occurs gradually and the chicks are immobile. We demonstrate here that a nictitating membrane response conditioning paradigm can be successfully used with 4-day-old chicks. The response is robust and discrete enough to be manipulated in later work predicting relations between neuronal and behavioral events.
\end{abstract}

Because the neuropharmacology of the domestic chick has been thoroughly examined (Spooner \& Winters, 1966) and its neuroanatomy, both mature and developing, has been delineated in great detail (Pearson, 1972), the chick has become a useful subject for the study of both learning and developmental processes. A wide variety of behavioral tasks have been used to study learning and development in the domestic chick (Bateson, 1974; Cherkin \& Lee-Teng, 1965; Peters \& Isaacson, 1963). However, in most of these tasks learning takes place within one or very few trials. Since many forms of learning are not one-trial phenomena, it would also be desirable to study the chick using a paradigm where learning occurs more gradually.

A paradigm which may be applicable to the chick was developed by Gormezano (Gormezano, Schneiderman, Deaux, \& Fuentes, 1962) to study associative learning processes in the rabbit. Basically, this paradigm involves using either an air puff or facial shock to classically condition the nictitating membrane (NM) response to a tone in a normal, intact animal. What is of particular interest is that

This study was partially supported by the V.A. Medical Research Service, by a National Institute of Health Postdoctoral Fellowship (1 F02 NS55862-01) to Steven R. Coates, and by NSF Grant BNS76-17370 to R. F. Thompson. We gratefully acknowledge the support of Richard F. Thompson, Department of Psychobiology, University of California, Irvine. Requests for reprints should be sent to Joel L. Davis, Department of Psychobiology, Veterans Administration Hospital, Sepulveda, California 91343. the paradigm lends itself to studying the ontogeny of learning. Studies have shown that the course and character of rabbit NM response conditioning can be significantly altered simply by varying training and stimulus variables (e.g., Gormezano, 1966, 1972; Gormezano \& Moore, 1969). In addition, this paradigm has been successfully used on animals other than rabbit (Gruber \& Schneiderman, 1975; Patterson, Olah, \& Clement, 1977). Finally, Thompson has pointed out (Thompson, Berger, Cegavske, Patterson, Roemer, Teyler, \& Young, 1976) that the NM conditioning paradigm is an excellent preparation for studying the neuronal basis of learning in rabbit. The present study attempted to determine whether this NM response conditioning paradigm could be used effectively on chicks, and, if so, whether it could make a suitable preparation for the study of neuronal and biochemical processes that correlate with learning and development.

\section{METHOD}

\section{Subjects and Apparatus}

A total of 12 White-Leghorn cockerels, obtained from a local hatchery (Pace/Setter Products, Inc., Strain K-137, Alta Loma, California) were used as subjects. At the onset of the experiment the chicks were $98 \pm 10 \mathrm{~h}$ old. They were housed individually in cartons $(8.5 \mathrm{~cm}$ in diameter $\times 16.5 \mathrm{~cm}$ deep) and allowed free access to water and starter mash when not in the testing chambers, which consisted of two adjacent file drawers, ventilated and fully lined with foam rubber. The two speakers located inside each chamber were used to continuously deliver a white noise to mask extraneous sounds or to present the CS, an $85-\mathrm{dB} 1,000-\mathrm{Hz}$ tone. The UCS was a series resistance-regulated constant current from a 2-pole Coulbourn shocker (Model E13-33) that was capable of 
evoking an NM response. The current was administered through subcutaneously placed stainless steel No. 0 insect pins located next to the outer and inner canthi of the right eye. All NM movements were recorded on a Grass polygraph as voltage changes from a minitorque potentiometer with a lever arm hooked via a fine thread to either a 6-0 nylon or silk (Ethilon) loop previously sutured near the outer edge of the NM of the chick's right eye. The polygraph was calibrated before each subject was run so that $1 \mathrm{~mm}$ of NM movement caused $2 \mathrm{~mm}$ of pen deflection.

\section{Procedure}

The subjects were run in pairs for 2 consecutive days, with the first experimental day commencing at $98 \pm 10 \mathrm{~h}$ posthatch. On each day, each subject was initially immobilized by being firmly wrapped in 1-in.-thick foam rubber and bound with masking tape. Only the subject's head was allowed to protrude from this encasement. The head was then gently turned to the left, pressed back against the foam rubber, and secured by taping the beak to the foam rubber, leaving only the right eye exposed and free to move. Once immobilized, the subject was clamped to a ring stand and the thread from the potentiometer was hooked to the chick's NM. The current for the UCS was set each day to a level (typically $0.1-0.2 \mathrm{~mA}$ ) which was just above the threshold for eliciting an NM response from both subjects. The same level of current was used for both subjects. Finally, the subjects were placed in the running chambers, the white noise was initiated, and the chambers were closed.

On Day 1, after being placed in the running chambers with the white noise on, the subjects were given 20 to $40 \mathrm{~min}$ in which no stimuli were presented in order to habituate them to the experimental situation. At the end of this habituation period, conditioning was begun.

The subjects were randomly assigned to one of two stimulus conditions (i.e., paired or unpaired) until there were six subjects in each condition. Each subject was conditioned under the same stimulus condition for both experimental days. In the paired stimulus condition, a total of 210 trials per day was used. During a trial, the CS was presented for $350 \mathrm{msec}$. Approximately $250 \mathrm{msec}$ after CS onset, the UCS was presented. The CS and UCS terminated simultaneously $100 \mathrm{msec}$ after UCS onset. A randomly varying intertrial interval of 50,60 , or $70 \mathrm{sec}$ was used for these paired trials. In the unpaired stimulus condition, a random sequence of $\mathbf{4 2 0}$ trials per day was used for each subject, with a trial consisting of presentation of either the CS or the UCS alone. An equal number of CS and UCS trials was used. In the 210 unpaired CS trials, stimulus duration was $350 \mathrm{msec}$. For the 210 unpaired UCS trials, stimulus duration was $100 \mathrm{msec}$. Randomly varying intertrial intervals of 20,30 , and $40 \mathrm{sec}$ were used with the unpaired trials. The unpaired stimulus condition had a dual purpose. First, the unpaired CS trials served to determine whether the CS, per se, was capable of eliciting NM responses. Second, the unpaired UCS trials served as a control for sensitization to facial shock.

\section{RESULTS}

All NM responses were measured by hand from polygraph records. A CR was defined as any temporal NM movement greater than $0.5 \mathrm{~mm}$ which occurred after the onset of the CS, but before the onset of the UCS for the paired trials, and within $250 \mathrm{msec}$ after the onset of the CS in the unpaired trials. In order to simplify the analysis of the NM responses, the 210 trials in the paired stimulus condition and the $210 \mathrm{CS}$-alone and $210 \mathrm{UCS}$-alone trials in the unpaired stimulus condition were arbitrarily separated into blocks of 15 trials.
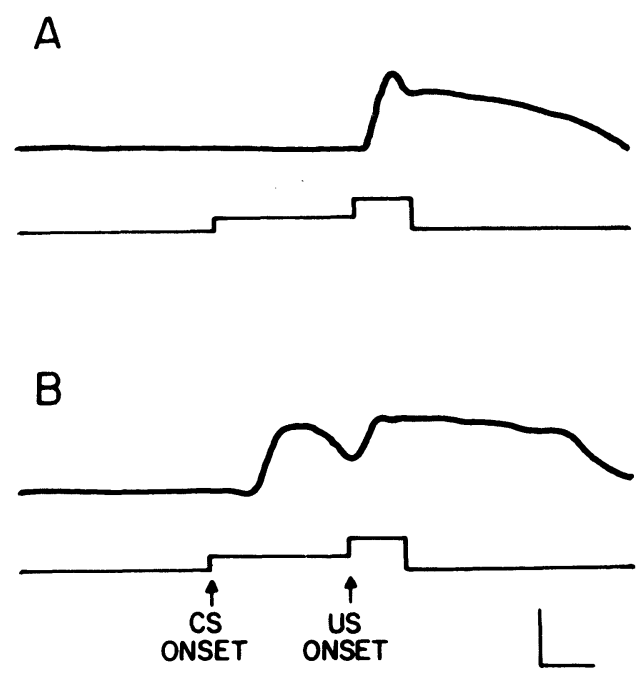

Figure 1 (A) Example of typical UCR. Onset within 10-20 msec. (B) Example of typical CR. Onset more variable and peak less distinct. For both $A$ and $B$, the horizontal reference line equals $100 \mathrm{msec}$ and the vertical reference line equals $10 \mathrm{~mm}$.

The UCR to shock onset always occurred within 10-20 msec. It consisted of a rapid movement, typically reaching a peak of $5-10 \mathrm{~mm}$ within $20 \mathrm{msec}$ after shock onset (Figure 1A). This UCR pattern remained constant over trial blocks. The peak was usually followed by a plateau of approximately $200 \mathrm{msec}$ and a gradual return to baseline. In contrast, the CRs were much more variable (Figure 1B). They were observed to begin throughout the $250 \mathrm{sec}$ stimulus period. The CRs of the NM were slower and weaker than the UCRs and rarely showed distinct peaks. Visual inspection revealed no dramatic differences between CRs produced early and late in conditioning sessions.

Figure 2 provides a comparison of latencies of $C R$ onset from CS onset over Days 1 and 2. The mean CR latency for Day 1 was $201.2 \mathrm{msec}(\mathrm{SD}=9.93$,

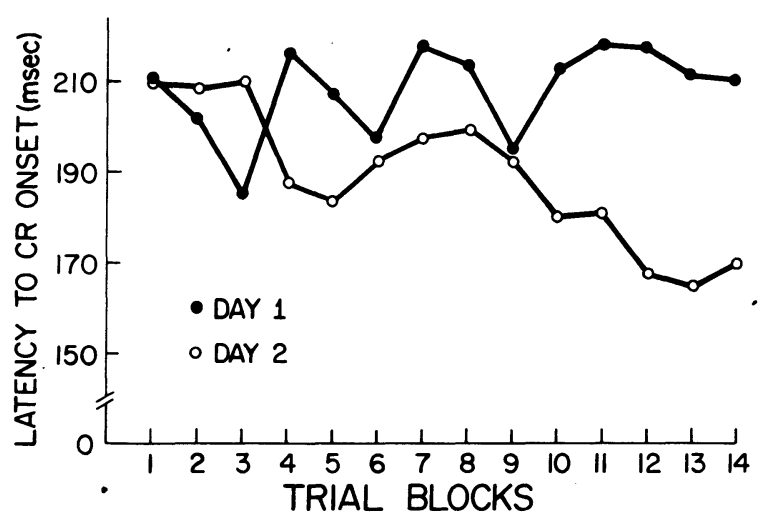

Figure 2. Comparison of latencies for Days 1 and 2 of $C R$ onset measured from start of CS. 
$\mathrm{N}=14)$ and for Day 2 was $189.3 \mathrm{msec}(\mathrm{SD}=14.65$, $N=14)$. This difference is significant $(t=13.55$, $\mathrm{p}<.01)$. It might be noted that, for rabbits, CRs typically develop (or occur) at the end of the CS period and move forward in time. Rarely, if ever, do CRs occur throughout the CS period as they do in the chick.

An analysis was made of the percentage of CRs occurring within each block of paired and unpaired trials on each day. The percentage of CRs was significantly greater for the paired trials than for the unpaired trials, $F(1,10)=12.29, p<.006$. Also, there were significantly more CRs on Day 2 than on Day 1 , $\mathrm{F}(1,10)=17.18, \mathrm{p}<.002$, and these CRs changed significantly as a function of trial blocks, $F(13,130)$ $=9.95, \mathrm{p}<.001$. The means and standard deviations of the percentage of CRs for the paired and unpaired trials on each day are presented in Table 1 . While the interaction among these means was significant, $\mathrm{F}(1,10)=13.39, \mathrm{p}<.004$, a post hoc analysis of this interaction using Tukey's HSD test indicated that the significance of these differences was primarily due to the rather substantial increase in the percentage of CRs occurring on Day 2 for the paired trials $(p<.01)$. None of the other means differed significantly from each other.

The analysis of the CRs in terms of trial blocks revealed significant differences in the development of CRs over blocks for the paired and unpaired trials, $F(13,130)=9.47, p<.001$. Also, the development of CRs over blocks was significantly different for each day, $F(13,130)=2.27, p<.01$. But what is more important is that the relationship of $C R$ development between the paired and unpaired trials changed significantly as a function of day $F(13,130)$ $=2.84, p<.001$. Figure 3 shows the percentage of CRs which occurred in each block on each day for the paired and unpaired trials. It can be seen from Figure 3 that the curves for the unpaired trials on Days 1 and 2 are very similar and reflect little change in CR development. While the anlaysis in general indicated no significant differences between the paired and unpaired trials on Day 1, the Day 1 curve in Figure 3 for the paired trials shows a small, but consistent, increase in CRs over blocks. This increase is particularly evident for the last six blocks. However, a substantial change in CRs over blocks is evident only in the Day 2 curve for the paired trials. A trend analysis of the interaction depicted in Fig-

Table 1

Means and Standard Deviations of the Percentage of CRs Occurring on Paired and Unpaired Trials Across Days

\begin{tabular}{clcr}
\hline Trial & & Day 1 & Day 2 \\
\hline \multirow{2}{*}{ Paired } & Mean & 8.49 & 31.43 \\
& SD & 9.72 & 18.93 \\
\multirow{2}{*}{ Unpaired } & Mean & 6.67 & 8.10 \\
& SD & 6.00 & 6.91 \\
\hline
\end{tabular}

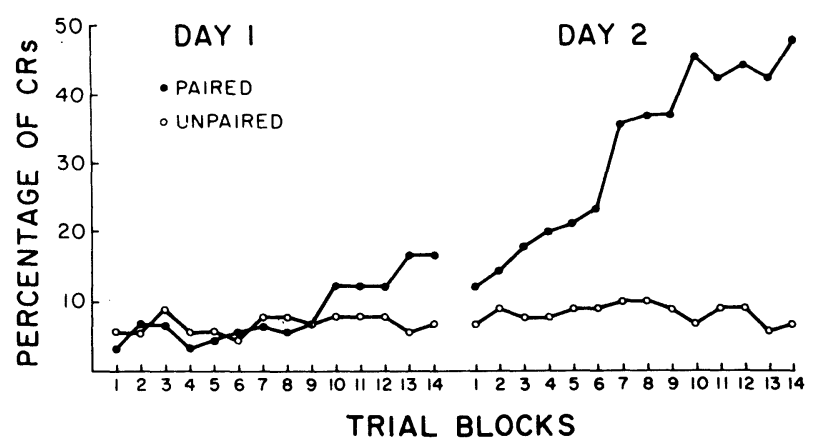

Figure 3. Percentage responses for the paired and unpaired trials as a function of trial blocks on Days 1 and 2.

ure 3 indicated that the development of CRs for the paired trials on Day 2 was primarily linear in nature, $\mathrm{F}(1,10)=10.89, \mathrm{p}<.008$. However, the cubic component was also significant, $F(1,10)=5.04$, $\mathrm{p}<.05$.

Finally, the period of time occurring $250 \mathrm{msec}$ prior to the onset of the CS was analyzed for the presence of spontaneous NM movement. The percentage of spontaneous NM responses for both stimulus conditions was consistently low for both days of running. No significant differences were found between the paired and unpaired stimulus groups for either day.

Figure 4 shows that the percentage of spontaneous responses $250 \mathrm{msec}$ prior to the onset of the CS starts out around $6 \%$ for both paired and unpaired controls. Although rather higher than data reported for the rabbit, it is consistent between paired and unpaired groups. Interblock variability is high. Mean percent spontaneous responses for the experimental group $(\mathrm{N}=14)$ are $3.56(\mathrm{SD}=2.60)$ and 2.69 $(\mathrm{SD}=2.82)$ for Days 1 and 2 . The control group $(\mathrm{N}=14)$ emitted $4.52(\mathrm{SD}=2.59)$ and 3.56 $(\mathrm{SD}=2.51)$ mean percent spontaneous responses on Days 1 and 2.

\section{DISCUSSION}

The results of the present study clearly show that the NM response conditioning paradigm can be used as an effective means for studying learning in the chick. The chick's NM response to facial shock was found to be both robust and discrete with a short latency-to-onset and a steep rise to peak amplitude. the tone CS appears to be quite capable of producing a CR which is consistent with the research on rabbit (e.g., Berger, Alger, \& Thompson, 1976; Gormezano et al., 1962). Spontaneous NM responses were consistently low, never exceeding $5 \%$ in either the paired or the unpaired stimulus condition.

Overall nonassociative rates of responding in this preparation appear to be low. For example, there is an absence of a large number of CRs during the initial unpaired trials (see Figure 3) and a lack of 


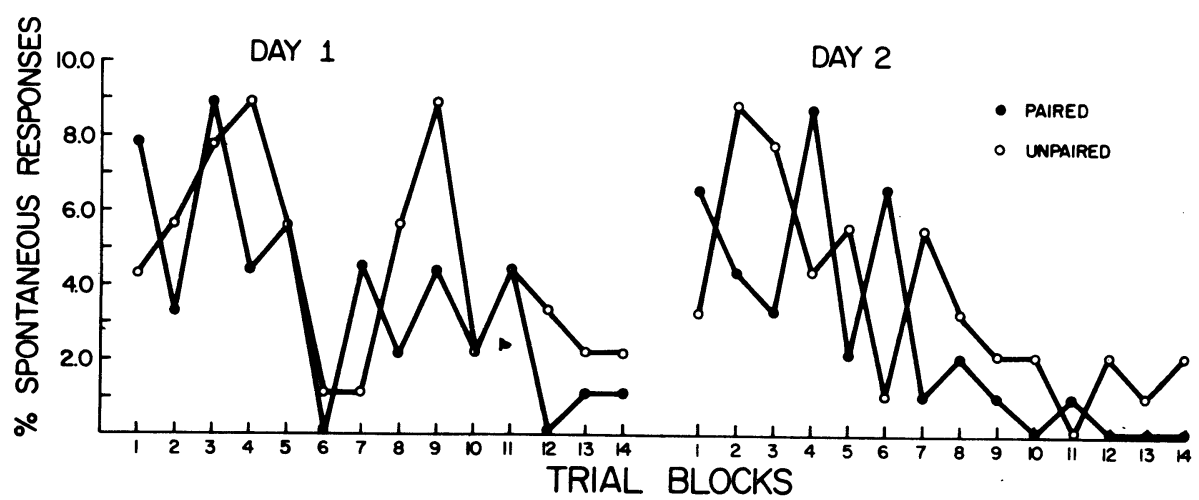

Figure 4. Percentage of spontaneous responses over Days 1 and 2.

any significant change over trials in either the response amplitude to the shock in the unpaired UCS trials or the frequency of response to the tone in the unpaired CS trials. Finally, we noted that the presentation of the CS produced a response approximately $8 \%$ of the time, which appears to be higher in the chick than in the rabbit. Gormezano et al. (1962) reported that for rabbits NM responses occurred on less than $5 \%$ of the unpaired CS presentations.

Figure 4 indicates a downward trend in the number of spontaneous responses over each day, although this may be partially obscured by the interblock variability. One possibility is that this may be a habituation effect to the UCS. Initially, each time the shock was presented it raised the chick's level of arousal, and blinking, therefore, increased. As shocks continued over trials, their influence decreased and the chick returned to a less aroused state. Thus, the decrease in spontaneous responses was due to UCS habituation. If this possibility is correct, of course, it implies that only the last blocks in each day were representative of the chick's normal spontaneous response level, although this level would be comparable to that found in the rabbit literature. Unfortunately, without the existence of UCS-only and no-stimulus groups to compare, the possibility of a habituation effect to the UCS remains to be proven.

It would seem that chicks are capable of gradual "associative" learning and that in the present study this learning is primarily linear in nature. However, what is interesting is that most of the learning appears to have occurred on Day 2. While some. learning seems to have taken place on Day 1 , it is hardly noticeable. The rather dramatic difference in behavior between Day 1 and Day 2 raises an important question for future research. Perhaps this behavioral difference is primarily due to maturational differences in the chick's capacity to make associations or is an artifact of the particular stimulus parameters employed in the present study. We are also considering a consolidation hypothesis as an explanation.

We feel this study demonstrates that the conditioning of the chick NM response is a reliable model for studying behavioral and neural plasticity.

\section{REFERENCES}

Bateson, P. Length of training, opportunities for comparison, and imprinting in chicks. Journal of Comparative and Physiological Psychology, 1974, 86, 586-589.

Berger, T. W., Alger, B. G., \& Thompson, R. F. Neuronal substrate of classical conditioning in the hippocampus. Science, 1976, 192, 483-485.

Cherkin, A., \& Lee-Teng, E. Interruption by halothane of memory consolidation in chicks. Federation Proceedings, 1965, 24, 328.

Gormezano, I. Classical conditioning. In J. B. Sidowski (Ed.), Experimental methods and instrumentation in psychology. New York: McGraw-Hill, 1966.

GORMEZANO, I. Investigations of defense and reward conditioning in the rabbit. In A. H. Black \& W. F. Prokasy (Eds.), Classical conditioning II. New York: Appleton-Century-Crofts, 1972.

Gormezano, I., \& Moore, J. W. Classical conditioning. In M. H. Marx (Ed.), Learning processes. London: Macmillan, 1969.

Gormezano, I., Schneiderman, N., Deaux, E., \& Fuentes, I. Nictitating membrane: Classical conditioning and extinction in the albino rabbit. Science, 1962, 138, 33-34.

Gruber, S. H., \& Schnemerman, N. Classical conditioning of the nictitating membrane response of the lemon shark. Behavior Research Methods \& Instrumentation, 1975, 7, 430-434.

Patterson, M. M., Olah, J., \& Clement, J. Classical nictitating membrane conditioning in the awake, normal, restrained cat. Science, 1977, 196, 1124-1125.

Pearson, R. The avian brain. London: Academic Press, 1972.

Peters, J., \& Isaacson, R. Acquisition of active and passive responses in two breeds of chickens. Journal of Comparative and Physiological Psychology, 1963, 56, 793-796.

SPOONER, C. E., \& WinTERs, W. D. Neuropharmacological profile of the young chick. International Journal of Neuropharmacology, 1966, 5, 217-236.

Thompson, R. F., Berger, T. W., Cegavske, C. F., Patterson, M. M., Roemer, R. A., Teyler, T. J., \& Young, R. A. The search for the engram. American Psychologist, 1976, 31, 208-227.

(Received for publications June 29, 1977; revision accepted October $4,1977$. 